\title{
Relationship between inhibin $A$ and $B$, estradiol and follicle growth dynamics during ovarian stimulation in normo-ovulatory women
}

\author{
Femke P Hohmann ${ }^{1}$, Joop S E Laven ${ }^{1}$, Frank H de Jong ${ }^{2}$ and Bart C J M Fauser ${ }^{1,3}$ \\ ${ }^{1}$ Division of Reproductive Medicine, Department of Obstetrics and Gynecology, ${ }^{2}$ Division of Endocrinology, Department of Internal Medicine, \\ Erasmus Medical Center, Rotterdam, The Netherlands and ${ }^{3}$ Department of Reproductive Medicine, University Medical Center, Utrecht, The Netherlands \\ (Correspondence should be addressed to Joop S E Laven; Email: j.laven@erasmusmc.nl)
}

\begin{abstract}
Objective: To investigate the relationship between serum concentrations of inhibin A, inhibin B and estradiol $\left(\mathrm{E}_{2}\right)$ and the number of developing follicles during the administration of exogenous follicle-stimulating hormone (FSH) in various regimens in normo-ovulatory volunteers and to evaluate if inhibins act as suitable markers for the number of developing follicles during ovarian stimulation. Design and methods: Serial hormone determinations and assessment of follicle numbers were carried out during unstimulated cycles and during various interventions with exogenous FSH. Subjects were randomized for FSH administration into the following groups: a single high dose ( $375 \mathrm{IU}$ ) during the early follicular phase (group A), 5 consecutive low doses (75 IU/day) starting in the mid follicular phase (group B) or daily low doses (75 IU/day) during the early to late follicular phase (starting on cycle days 3, 5 or 7; groups $\mathrm{C}$, D and E respectively).

Results: Extending the FSH window increases the number of small antral follicles and hence inhibin B serum concentrations. If such an intervention results in multi-follicular growth, mid follicular phase inhibin B $(P=0.001)$ as well as late follicular phase inhibin B and inhibin A levels are significantly $(P<0.05$ and $P<0.01$ respectively) increased compared with mono-follicular cycles or the natural cycle. Although mid follicular inhibin B levels correlated well with the number of small antral $(P<0.05)$ and pre-ovulatory $(P<0.001)$ follicles in the late follicular phase, mid follicular inhibin $A$ and estradiol serum concentrations only correlated with the number of pre-ovulatory follicles $(P<0.001$ and $P<0.01$ respectively $)$.

Conclusions: The present data extend our understanding of the relationship between follicle dynamics, serum inhibins and FSH during ovarian hyperstimulation. However, although mid follicular inhibin B does correlate with the number of developing follicles, it does not facilitate the identification of women at risk for multiple follicle development.
\end{abstract}

European Journal of Endocrinology 152 395-401

\section{Introduction}

Inhibins are principally produced in the ovary by granulosa cells and selectively inhibit follicle-stimulating hormone (FSH) secretion by the pituitary (1). Inhibins are dimeric glycoproteins produced by the gonads, consisting of an $\alpha$ subunit linked through disulfide binding with either a $\beta_{A}$ or $\beta_{B}$ subunit. The resulting $\alpha \beta_{A}$ heterodimer is referred to as inhibin $A$, whereas the $\alpha \beta_{B}$ protein constitutes inhibin B (2). Inhibin A seems to be the predominant form produced during the late follicular and luteal phases of the normal menstrual cycle, whereas inhibin B is the predominant form during the early and mid follicular phases of the cycle $(2,3)$.

Recent studies in normo-ovulatory women have shown convincingly that inhibin B is predominantly secreted by granulosa cells of pre-antral and small antral follicles and hence its concentration increases during the luteo-follicular transition (4). Inhibin B levels are highest during the mid follicular phase and decline during the late follicular phase $(5,6)$. A transient rise in inhibin B levels coincided with the mid-cyclic luteinizing hormone (LH) and FSH surge. Thereafter, inhibin B levels decline further to a nadir in the mid luteal phase $(5,7)$. Declining inhibin A levels during the late luteal phase seem to be the predominant regulator of rising FSH serum levels during the luteo-follicular transition and hence contribute to the dynamic changes within a menstrual cycle $(8-11)$. In contrast, high inhibin B concentrations during the early follicular phase are responsible for the decline in FSH serum levels closing the FSH window and assuring single dominant follicle selection (12). This specific 
differential pattern of inhibin A and inhibin B secretion is established during early puberty and remains constant throughout reproductive life (13).

Since the size of the cohort of recruited follicles appears to be related to the size of the primordial follicle pool (14), inhibin B may constitute a suitable marker of ovarian ageing $(15,16)$. Moreover, inhibin B serum levels have been suggested to predict poor response to ovarian hyperstimulation in in vitro fertilization (IVF) patients (17). Unfortunately, more detailed analyses concluded that early follicular phase inhibin B serum levels are only of limited value in predicting response during ovarian hyperstimulation (18-21). Dynamic inhibin B testing with FSH stimulation $(22,23)$ or gonadotropin releasing hormone (GnRH) agonist administration (24) appears to correlate better with ovarian response. A good correlation was also observed between inhibin $\mathrm{B}$ concentrations during ovarian hyperstimulation and the number of oocytes retrieved $(25,26)$.

However, most, if not all, of the aforementioned studies used GnRH agonists to suppress endogenous gonadotropins and consequently baseline inhibin B levels are decreased (27). Hence, results from these studies might not be readily applicable to stimulation protocols used for ovulation induction or minimal ovarian hyperstimulation in conjunction with intrauterine insemination during which GnRH analogs are not usually applied. The current study was designed to study the relationship between serum concentrations of inhibin A and inhibin B and the number of developing follicles during various ovarian hyperstimulation protocols without previous down regulation using a GnRH agonist.

\section{Materials and methods}

\section{Subjects}

This study was approved by the local Ethics Review Committee. A total group of 63 healthy volunteers was selected from responders to advertisements in local newspapers and interviews on the local radio and television. Written informed consent was obtained from each participant, and all subjects were paid for participation, as previously published $(28,29)$.

Inclusion criteria were: (i) a history of regular menstrual cycles (cycle length 25-32 days); (ii) age range of 19 to 35 years; (iii) body mass index (BMI) 18$27 \mathrm{~kg} / \mathrm{m}^{2}$; (iv) mid luteal progesterone concentrations (assessed 7 days prior to expected menses) of at least $18 \mathrm{nmol} / \mathrm{l}$ and $(\mathrm{v})$ no previous use of medication or oral contraceptives during at least 3 months prior to the study. Patients with a past history of any endocrine disease or infertility were excluded. All participants either used non-steroidal contraception (intrauterine devices, condoms or prior tubal ligation) or refrained from sexual intercourse during the study period.

\section{Interventions}

The first 23 subjects were studied during a natural cycle, followed by an intervention cycle (study 1, groups $\mathrm{A}$ and B). The remaining 40 volunteers were studied during a single intervention cycle (study 2, groups C, D, E) $(28,29)$.

The natural cycle was assessed by means of daily transvaginal ultrasound scans (TVS) and daily blood sampling starting on day 12 after the assessed LH surge in the pre study cycle and concluding on the day of ovulation as assessed by TVS. Normal ovulation was confirmed by assessment of elevated progesterone levels $(>18 \mathrm{nmol} / \mathrm{l}) 6$ or 7 days later (30). The LH surge in the pre study cycle was determined using a urinary LH self-test (Clear-plan One Step, Unipath Ltd., Bedford, Beds, UK) starting 10 days after the onset of the previous menses.

Study 1 (groups $\boldsymbol{A}$ and B) For the subjects who were followed during a natural cycle, a second series of daily TVS and blood sampling started at day $10(\mathrm{LH}+10)$ after the LH surge in the control cycle. Women were randomly assigned to group A or B as published previously (28). All participants received exogenous urinary FSH (Metrodin-HP, Serono Benelux BV, The Hague, The Netherlands) from the same batch. Group A received a single dose of 375 IU urinary FSH s.c. at day $\mathrm{LH}+14$, effectively increasing the FSH concentrations above the presumed threshold without affecting the length of the FSH window (31). Group B received a similar total dose in 5 consecutive injections of $75 \mathrm{IU} /$ day urinary FSH s.c. starting on day $\mathrm{LH}+19$, thereby preventing decremental serum FSH concentrations in the mid to late follicular phase and thus widening the $\mathrm{FSH}$ window. FSH was administered shortly after the daily blood withdrawal. Daily TVS as well as blood sampling were continued until the day of sonographically assessed ovulation. Normal ovulation was confirmed by assessment of elevated progesterone levels 7 days later.

Study 2 (groups C, D and E) The remaining 40 subjects were randomly assigned to groups C, D and E, as published previously (29). All these subjects received a daily fixed dose of 75 IU recombinant FSH (recFSH; Gonal-F, Serono Benelux BV) starting on day 3, 5 or 7 respectively, until the day of human chorionic gonadotrophin (hCG) administration. As soon as the largest follicle reached a diameter of $18 \mathrm{~mm}$ or more a single dose of 5000 IU hCG (Profasi, Serono Benelux BV) was administered i.m. at $2200 \mathrm{~h}$ to induce ovulation. TVS as well as blood sampling were performed on a two daily basis starting on cycle day 3 until the largest follicle reached a diameter of $15 \mathrm{~mm}$ or more. Thereafter, ultrasound scans and blood sampling were performed daily until sonographically assessed ovulation. Ovulation was 
confirmed by blood sampling and TVS 8 days after hCG administration.

Sonographic imaging was performed using a 6.5 MHz transvaginal transducer (model EUB415/420; Hitachi Medical Corporation, Tokyo, Japan). The ovaries were localized and scanned as described previously (32). Follicle diameter was calculated as the mean diameter (measured in two dimensions when $<9 \mathrm{~mm}$ and measured in three dimensions when $>9 \mathrm{~mm}$ ), as published previously $(30,32)$. A dominant follicle was defined as a follicle with a diameter of $10 \mathrm{~mm}$ or more, whereas a pre-ovulatory follicle should measure $15 \mathrm{~mm}$ or more. This distinction is clinically important since not all follicles measuring $10 \mathrm{~mm}$ or more reach the pre-ovulatory stage. Sonographically assessed ovulation was defined as a decrease in size of $>50 \%$ of the largest follicle $(\geq 18 \mathrm{~mm})$.

\section{Hormone assays}

Blood samples were obtained by venepuncture and processed within $2 \mathrm{~h}$ after withdrawal. Serum was stored at $-20{ }^{\circ} \mathrm{C}$ until assayed. Serum levels of $\mathrm{LH}$ and FSH were measured using luminescence based immunoassays (Immulite, Diagnostic Products Corp., Los Angeles, CA, USA) whereas serum estradiol $\left(E_{2}\right)$ levels were measured using coated tube radioimmunoassays provided by the same supplier. Standards used in the gonadotrophin assays were based on WHO 2nd IRP 78/549 and WHO 1st IRP 68/40 for FSH and LH respectively. Sensitivities of the assays were $0.1 \mathrm{U} / \mathrm{l}$ for $\mathrm{FSH}$ and $\mathrm{LH}$, and $10 \mathrm{pmol} / \mathrm{l}$ for $\mathrm{E}_{2}$. Intra- and interassay coefficients of variation were less than $5 \%$ and $6 \%$ for $\mathrm{LH}$, less than $5 \%$ and $7 \%$ for $\mathrm{FSH}$ and less than $5 \%$ and $7 \%$ for $\mathrm{E}_{2}$ respectively.

Dimeric inhibin A and B levels were assessed using an immuno-enzymometric assay obtained from Serotec (Oxford, Oxon, UK), as described previously (6). The detection limit of the assay, defined as the amount of inhibin equivalent to the signal of the blank +3 s.D. of this signal, was $3.4 \mathrm{ng} / \mathrm{l}$ for both inhibin A and B. Intra- and interassay coefficients of variation were less than $8 \%$ and $15 \%$ for inhibin $A$ and less than $8 \%$ and $14 \%$ for inhibin B respectively. All samples from one subject were run within the same assay.

\section{Data analysis}

The early follicular phase was defined as day ${ }^{\mathrm{LH}+14}-$ day $^{\mathrm{LH}+18}$ for the natural cycle and for groups A and B (intervention study 1) and as cycle day (CD) $1-$ CD 5 for groups C, D and E (intervention study 2). The mid and late follicular phases were defined as day ${ }^{\mathrm{LH}+19}-$ day $^{\mathrm{LH}+23}$ and day ${ }^{\mathrm{LH}+24}-$ day ${ }^{\mathrm{LH}}$ surge (natural cycle, groups A and B) and CD 6-CD 10 and CD 11 day $^{\text {hCG }}$ (groups C, D and E) respectively. Data are presented as means and S.D. if distributed normally or as median and ranges if distributed otherwise. The early, mid or late follicular phase value of a subject is chosen to be the mean value in each phase, in order to prevent overrating of individual subjects in the calculations. Student's $t$-test statistics were performed on normally distributed data. Whenever a non-parametric distribution was found, groups were compared using the Mann-Whitney U-test. Comparisons of outcome measures between more than 2 groups were performed using the Kruskal-Wallis $H$-test for continuous data and using the $\chi^{2}$ test for binary variables. Comparisons of data over time between groups were carried out using analysis of variance (ANOVA). Correlation coefficients given are Spearman's. $P$ values are two-sided and 0.05 was considered to indicate statistical significance. Data were analyzed using a commercially available software package (SPSS, Chicago, IL, USA).

\section{Results}

\section{Baseline characteristics}

Sixty-three normo-ovulatory women entered the study protocol. In the first study, 11 and 12 subjects were assigned to groups $\mathrm{A}$ and $\mathrm{B}$ respectively. In the second study, 13, 13 and 14 subjects were allocated to groups C, D and E respectively. With regard to the distribution of age, cycle length and baseline endocrine serum concentrations of $E_{2}$ and inhibin $B$, no statistical differences existed between the groups (Table 1). FSH and inhibin A were comparable between groups A and $B$ and no significant differences were found when comparing groups $\mathrm{C}, \mathrm{D}$ and $\mathrm{E}$.

\section{Hormone concentrations}

Differences in mean early, mid and late follicular phase levels of inhibin B, inhibin $\mathrm{A}, \mathrm{E}_{2}$ and $\mathrm{FSH}$ between the natural cycle and the intervention groups A, B, C, D and $\mathrm{E}$ are depicted in Fig. 1. In the natural cycle, inhibin B levels showed a significant rise from the early follicular phase to their highest levels in the mid follicular phase $(P<0.01)$. Inhibin $\mathrm{A}$ and $\mathrm{E}_{2}$ levels increased significantly in the late follicular phase $(P<0.001$ and $P<0.001$ respectively). In group $\mathrm{A}$, FSH serum concentrations showed a significant decrease from the early to mid follicular phase $(P=0.001)$, with a subsequent decrease in inhibin $B$ concentrations from the early to late follicular phase $(P<0.05)$. Groups B, C and D (all starting exogenous FSH in the early follicular phase or at the beginning of the mid follicular phase) all showed an increase in inhibin B levels from the early to mid follicular phase $(P<0.01, P<0.05$ and $P<0.01$ respectively) without significant changes in $\mathrm{FSH}$ concentrations. Although inhibin $\mathrm{B}$ levels in group $\mathrm{E}$ showed an increase from the early to late follicular phase $(P<0.01)$, the increase started later with a significant increase from the mid to the late follicular 
Table 1 Baseline characteristics (median and range) in 63 healthy female normo-ovulatory volunteers participating in the study with various intervention regimens with exogenous FSH.

\begin{tabular}{|c|c|c|c|c|c|}
\hline & \multicolumn{5}{|c|}{ Intervention group } \\
\hline & \multicolumn{2}{|c|}{ Study 1} & \multicolumn{3}{|c|}{ Study 2} \\
\hline & $\mathrm{A}(n=11)$ & $\mathrm{B}(n=12)$ & $\mathrm{C}(n=13)$ & $\mathrm{D}(n=13)$ & $\mathrm{E}(n=14)$ \\
\hline Age (years) & $28(25-33)$ & $28(20-34)$ & $29(21-35)$ & $29(22-34)$ & $28(20-35)$ \\
\hline Cycle length (days) & $28(27-30)$ & $29(27-30)$ & $28(26-31)$ & $28(25-31)$ & $28(26-30)$ \\
\hline $\mathrm{FSH}(\mathrm{IU} / \mathrm{I})^{\star}$ & $5.1(3.9-6.0)$ & $5.1(3.6-7.7)$ & $6.5(2.8-13.5)$ & $6.3(3.3-9.8)$ & $7.7(5.4-13.1)$ \\
\hline $\mathrm{E}_{2}(\mathrm{pmol} / \mathrm{l})^{\star}$ & $156(102-230)$ & $143(106-259)$ & $127(64-220)$ & $175(91-404)$ & $137(109-264)$ \\
\hline Inhibin A (ng/l)* & $5(2-9)$ & $5(2-6)$ & $5(4-9)$ & $7(3-52)$ & $8(4-11)$ \\
\hline Inhibin B (ng/l)* & $98(29-221)$ & $154(68-234)$ & $87(21-192)$ & $130(12-213)$ & $114(57-179)$ \\
\hline
\end{tabular}

*All baseline endocrine parameters were assessed on cycle day 3 (pre-intervention cycle for group A and B, intervention cycle for groups C, D and E).

phase $(P<0.05)$. In all five intervention groups inhibin $\mathrm{A}$ and $\mathrm{E}_{2}$ levels increased during the follicular phase, all except group A showing a significant increase between early and mid follicular phase levels (inhibin $\mathrm{A}$ and $\mathrm{E}_{2}$ levels: $P<0.001$ and $P<0.001$, $P<0.001$ and $P<0.001, \quad P=0.001 \quad$ and $P<0.001$, and $P<0.05$ and $P<0.001$ for groups $\mathrm{B}, \mathrm{C}, \mathrm{D}$ and $\mathrm{E}$ respectively), and all groups showing a significant increase between mid and late follicular phase levels $(P<0.001$ and $P<0.001, P<0.001$ and $P<0.001, P<0.01$ and $P<0.01, P<0.001$ and $P<0.01$, and $P=0.001$ and $P=0.001$, for groups A, B, C, D and E respectively).

In the early follicular phase, group A showed a significant rise in FSH concentrations $(P<0.001)$, with a subsequent rise in inhibin $B$ concentrations $(P<0.001)$ compared with the natural cycle. Also group $\mathrm{C}$ showed increased FSH $(P<0.001)$ and inhibin $\mathrm{B}(P<0.01)$ concentrations compared with the natural cycle. In the mid follicular phase serum hormone levels in group A were comparable with the concentrations in the natural cycle. In groups B, C and D, however, inhibin $\mathrm{B}$, inhibin $\mathrm{A}, \mathrm{E}_{2}$ and $\mathrm{FSH}$ concentrations were all increased compared with the natural cycle (respectively $P=0.01, \quad P<0.01, \quad P<0.001$ and $P<0.01$ for group $B ; P<0.05, P<0.001$, $P<0.05$ and $P<0.001$ for group $C$ and $P=0.001$, $P<0.001, P<0.001$ and $P<0.001$ for group $D)$. Mid follicular inhibin B levels in group E were comparable with the natural cycle, whereas inhibin $A, E_{2}$ and FSH levels were increased $(P<0.001, P<0.05$ and $P<0.001$ respectively).

No differences were observed comparing the natural cycle and group A in the late follicular phase. The other intervention groups showed late follicular inhibin B levels comparable with the natural cycle, except for group $\mathrm{E}$, which showed a significant rise in inhibin $\mathrm{B}$ levels $(P<0.001)$. These intervention groups all showed a significant rise in late follicular inhibin A levels compared with the natural cycle $(P<0.01$, $P<0.001, P<0.001$ and $P<0.001$ for groups $B$, $\mathrm{C}, \mathrm{D}$ and E respectively). No differences were found in
$\mathrm{E}_{2}$ concentrations, except for a slight increase in group B $(P<0.05)$.

\section{Follicle growth and serum inhibin concentrations}

In the natural cycle the rise in serum inhibin B levels coincided with a similar increase in the number of small antral follicles with diameters ranging from 5 to $11 \mathrm{~mm}$ (Pearson's correlations between inhibin B and follicles ranging from 5 to $9 \mathrm{~mm}$ and from 9 to $11 \mathrm{~mm}$ : $\mathrm{r}=0.423, \quad P<0.001$ and $\mathrm{r}=0.316, \quad P=0.01$ respectively). Inhibin A increased only after a follicle of $15 \mathrm{~mm}$ or larger was detected during the late follicular phase (Pearson's correlations between inhibin $A$ and follicles ranging from 15 to $16 \mathrm{~mm}$ and from 17 to $18 \mathrm{~mm}: \mathrm{r}=0.357, P<0.05$ and $\mathrm{r}=0.427$, $P<0.01$ respectively).

Interventions $\mathrm{C}, \mathrm{D}$ and $\mathrm{E}$ all resulted in a significant increase $(P<0.01)$ in the number of follicles measuring $10 \mathrm{~mm}$ or more. In total, 24 subjects $(60 \%)$ from groups C, D and E showed multi-follicular growth (defined as $>1$ follicle measuring $>10 \mathrm{~mm}$ at the day of hCG administration). In multi-follicular cycles, mid follicular inhibin B levels were significantly elevated compared with mono-follicular cycles (median mid follicular inhibin B $245 \mathrm{ng} / \mathrm{l}$ (range $75-830$ ) vs $147 \mathrm{ng} / \mathrm{l}$ (range 57-291) for multi- and mono-follicular cycles, $P=0.001)$. In the late follicular phase median inhibin $\mathrm{B}$, inhibin $\mathrm{A}$ and $\mathrm{E}_{2}$ levels were elevated in multi-follicular cycles compared with the mono-follicular cycles (median late follicular inhibin B $230 \mathrm{ng} / \mathrm{l}$ (range 50-902) vs $113 \mathrm{ng} / \mathrm{l}$ (range 76-298), $P<0.05$; inhibin A $75 \mathrm{ng} / \mathrm{l}$ (range 14-185) vs $39 \mathrm{ng} / \mathrm{l}$ (range 14-57), $P<0.01$ and $\mathrm{E}_{2} \quad 886 \mathrm{pmol} / \mathrm{l}$ (range 221-2188) vs $664 \mathrm{pmol} / \mathrm{l}$ (range 310-807), $P<0.05$ respectively).

Table 2 shows the relation between median early, mid or late follicular phase levels of inhibin B, inhibin $\mathrm{A}, \mathrm{FSH}$ and $\mathrm{E}_{2}$ with the number of follicles of different size categories in the five intervention cycles. Only the early follicular inhibin $\mathrm{B}$ concentration correlated 

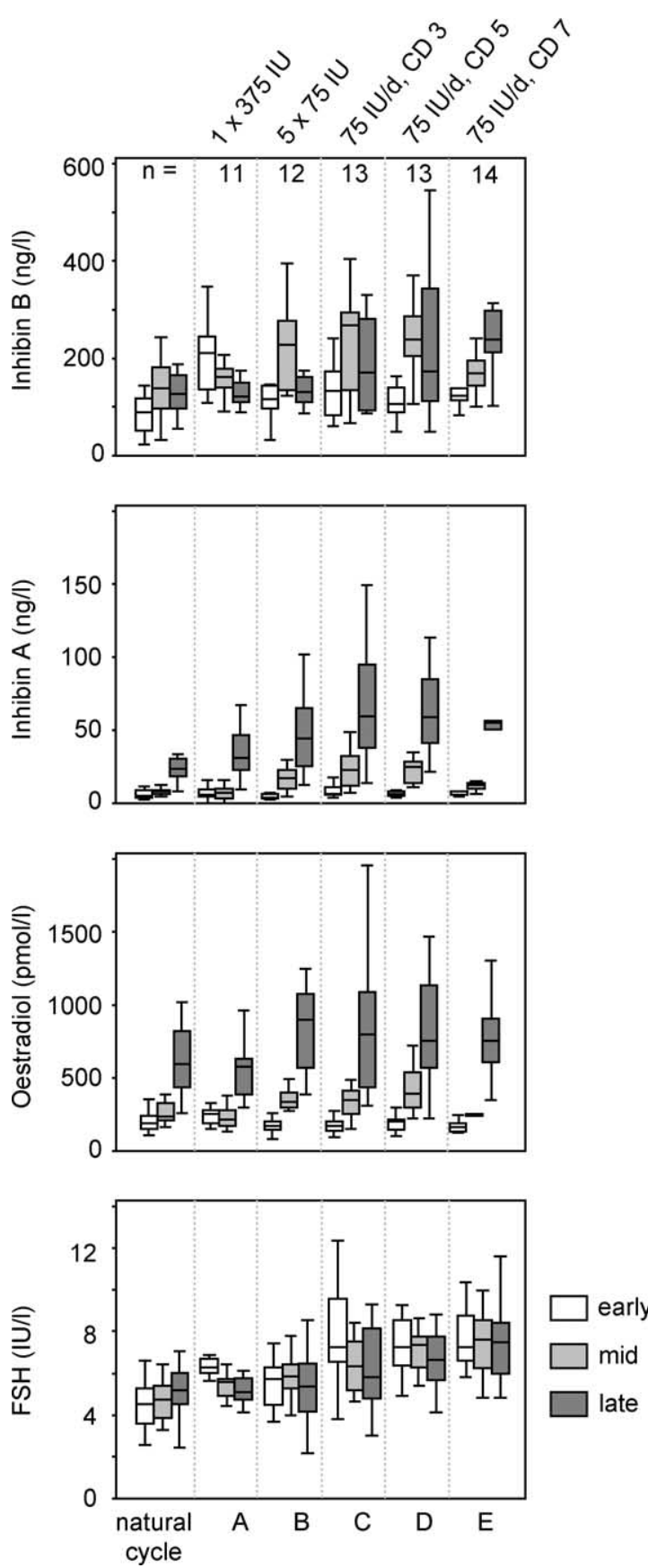

Figure 1 Box and whisker plots depicting mean concentrations during the early, mid and late follicular phase of inhibin $B$, inhibin $\mathrm{A}, \mathrm{E}_{2}$ as well as $\mathrm{FSH}$ in 63 normo-ovulatory women, comparing the natural cycle $(n=23)$ and five intervention cycles with exogenous FSH. Group A received $375 \mathrm{IU}$ FSH in a single dose in the early follicular phase $(n=11)$, group $\mathrm{B}$ received five consecutive doses of $75 \mathrm{IU}(75 \mathrm{IU} / \mathrm{d}) \mathrm{FSH}$ in the mid follicular phase $(n=12)$, and group $\mathrm{C}(n=13)$, group $\mathrm{D}(n=13)$ and group $\mathrm{E}$ $(n=14)$ received daily doses of $75 \mathrm{IU}(75 \mathrm{IU} / \mathrm{d}) \mathrm{FSH}$ commencing on cycle day (CD) 3, CD 5 or CD 7 respectively, until the administration of hCG in the late follicular phase. Boxes indicate 25th and 75th percentiles, with the horizontal line representing the median value. Whiskers span the range between the 5th and 95th percentiles of the data.
Table 2 Pearson's correlations ( $r$ ) between median early-, midand late-follicular phase levels of inhibin $B$, inhibin $A, F S H$ and $E_{2}$ and the number of follicles of different size categories in the late follicular phase $e^{\S}$ of various intervention cycles in 63 normoovulatory women.

\begin{tabular}{|c|c|c|c|}
\hline & $\begin{array}{c}\text { Number of } \\
\text { follicles } \\
5-10 \mathrm{~mm}\end{array}$ & $\begin{array}{l}\text { Number of } \\
\text { follicles } \\
10-15 \mathrm{~mm}\end{array}$ & $\begin{array}{l}\text { Number of } \\
\text { follicles } \\
15-20 \mathrm{~mm}\end{array}$ \\
\hline \multicolumn{4}{|c|}{ Inhibin B (ng/l) } \\
\hline Early & 0.260 * & $-0.256^{\star}$ & 0.022 \\
\hline Mid & $0.293^{*}$ & $0.352^{* *}$ & $0.539 * \star \star$ \\
\hline Late & 0.128 & $0.536^{\star \star \star}$ & $0.636^{* * *}$ \\
\hline \multicolumn{4}{|c|}{ Inhibin A (ng/l) } \\
\hline Early & -0.103 & -0.054 & 0.049 \\
\hline Mid & 0.135 & 0.084 & $0.424 * \star *$ \\
\hline Late & 0.106 & 0.378 ** & $0.755^{\star \star \star}$ \\
\hline \multicolumn{4}{|c|}{$\mathrm{FSH}(\mathrm{IU} / \mathrm{I})$} \\
\hline Early & -0.158 & 0.012 & 0.147 \\
\hline Mid & -0.044 & 0.202 & -0.073 \\
\hline Late & -0.162 & 0.018 & -0.042 \\
\hline \multicolumn{4}{|c|}{$\mathrm{E}_{2}(\mathrm{pmol} / \mathrm{l})$} \\
\hline Early & -0.056 & -0.099 & -0.039 \\
\hline Mid & 0.162 & 0.044 & $0.336 * *$ \\
\hline Late & 0.086 & $0.360^{\star *}$ & $0.737^{* * *}$ \\
\hline
\end{tabular}

slightly with the number of small follicles at the end of the follicular phase. In contrast, in the mid follicular phase inhibin B levels, as well as inhibin A levels, correlated with the number of developing larger follicles. In the late follicular phase a strong correlation was found between inhibin $\mathrm{B}$, inhibin $\mathrm{A}$ and $\mathrm{E}_{2}$ levels and the number of larger follicles at the end of the follicular phase.

\section{Discussion}

The present study in normo-ovulatory women confirms that inhibin $\mathrm{B}$ is indeed mainly produced by small antral follicles and hence inhibin B levels increase during the early to mid follicular phases. Thereafter, inhibin B levels decline during the late follicular phase. Inhibin A is predominantly produced by the pre-ovulatory follicle and serum concentrations are therefore high during the late follicular phase. An increase in FSH stimulation during the early follicular phase induces an increased growth of small antral follicles and hence elevated inhibin B concentrations. If this increase in FSH is long enough to extend the FSH window (the period during which FSH levels are above the threshold for ovarian stimulation $(31,33)$ ), the intervention can result in ongoing multi-follicular growth and hence an increase in both inhibin B and inhibin A. However, if the selection of the single dominant follicle is not affected, serum inhibin B levels return to normal and inhibin A levels remain comparable with serum levels in the natural cycle.

In the natural cycle serum inhibins showed the expected pattern. After the initial rise in FSH a number 
of small antral follicles is recruited and subsequently inhibin B is produced. Thereafter, the dominant follicle is selected and smaller follicles from the recruited cohort become atretic. Hence, inhibin B levels decrease $(2,3)$. Inhibin $A$ and $E_{2}$ levels increase after the dominant follicle selection $(12,22,34)$. Inhibin B serum concentrations in the natural cycle showed a biphasic pattern in the mid to late follicular phase. This pattern correlated highly with the number of follicles measuring up to $11 \mathrm{~mm}$, whereas the number of follicles larger than $11 \mathrm{~mm}$ was relatively constant in this phase of the cycle, suggesting that inhibin B mainly originates from follicles up to $11 \mathrm{~mm}$. A similar relationship has been reported recently in menstrual cycles of normo-ovulatory women (35).

In the current study, inhibin B levels were increased in all intervention cycles during which exogenous FSH was administered. Moreover, in those cycles with multifollicular development the highest levels were recorded. When the FSH window is effectively broadened more small follicles will emerge from the recruitable pool (28). Since inhibin B is mainly produced by small antral follicles up to $12 \mathrm{~mm}$ in size it might constitute a marker for multiple follicle development (36). In the current study, inhibin B serum concentrations during the early and mid follicular phases were indeed significantly correlated with the number of small developing follicles. Moreover, mid and late follicular phase inhibin $B$ levels were higher in those cycles which resulted in multi-follicular development, reflected in significant correlations in mid and late follicular phase inhibin B levels and the number of larger follicles at the end of the follicular phase (the day of the LH surge or the day of hCG administration). Apparently, mid and late follicular phase inhibin B concentrations during ovarian (hyper) stimulation constitute a marker for the number of developing follicles $(25,26)$.

Prediction of those women who may under- or overrespond to ovarian (hyper) stimulation protocols is of clinical importance. During ovarian stimulation (ovulation induction or ovarian hyperstimulation) it has been shown that the number of follicles measuring $12 \mathrm{~mm}$ or more at the day of hCG administration is strongly correlated with the incidence of high order multiple pregnancies $(37,38)$. Similarly, $E_{2}$ serum concentrations are strongly correlated with adverse outcome (38). Since mid follicular inhibin B serum concentrations were correlated both with the number of follicles measuring $10 \mathrm{~mm}$ or more as well as with multi-follicular development, inhibin B might also constitute a predictor of multiple gestation during ovarian hyperstimulation. Ideally, such a predictor should be sufficiently accurate and distinct in time from the moment that stimulation protocols are commenced (39). Consequently, based on early follicular phase inhibin B serum levels, treatment might be optimized since women at risk for ovarian hyperstimulation syndrome and multiple pregnancies might be more easily identified prior to treatment. Unfortunately, in the current study as in others, the basal inhibin B serum levels did not correlate with the final pre-ovulatory number of follicles $(18,19,39,40)$. Moreover, early basal as well as stimulated inhibin B levels seem to reflect the potential follicular development of the ovary, but are not significantly associated with the final oocyte number which is mainly determined by the antral follicle count and the basal FSH serum concentration (39). Therefore, inhibin B constitutes a poor marker in the risk assessment of women who might over-respond to treatment.

In conclusion, the present data extend our understanding of the relationship between follicle dynamics, serum inhibins and FSH levels during multiple dominant follicle development resulting from ovarian hyperstimulation with exogenous FSH. However, although mid follicular inhibin $B$ does correlate with the number of developing follicles, it does not facilitate the identification of women at risk for multiple follicle development.

\section{References}

1 Burger HG. Evidence for a negative feedback role of inhibin in follicle stimulating hormone regulation in women. Human Reproduction 19938 (Suppl 2) 129-132.

2 de Kretser DM, Hedger MP, Loveland KL \& Phillips DJ. Inhibins, activins and follistatin in reproduction. Human Reproduction Update 20028 529-541.

3 Laven JS \& Fauser BC. Inhibins and adult ovarian function. Molecular and Cellular Endocrinology $200422537-44$.

4 Roberts VJ, Barth S, el Roeiy A \& Yen SS. Expression of inhibin/ activin subunits and follistatin messenger ribonucleic acids and proteins in ovarian follicles and the corpus luteum during the human menstrual cycle. Journal of Clinical Endocrinology and Metabolism $1993771402-1410$.

5 Groome NP, Illingworth PJ, O’Brien M, Pai R, Rodger FE, Mather JP \& McNeilly AS. Measurement of dimeric inhibin B throughout the human menstrual cycle. Journal of Clinical Endocrinology and Metabolism 199681 1401-1405.

6 Schipper I, de Jong FH \& Fauser BC. Lack of correlation between maximum early follicular phase serum follicle stimulating hormone concentrations and menstrual cycle characteristics in women under the age of 35 years. Human Reproduction 1998 $131442-1448$.

7 Muttukrishna S, Fowler PA, Groome NP, Mitchell GG, Robertson WR \& Knight PG. Serum concentrations of dimeric inhibin during the spontaneous human menstrual cycle and after treatment with exogenous gonadotrophin. Human Reproduction $199491634-1642$.

8 Brannian JD, Stouffer RL, Molskness TA, Chandrasekher YA, Sarkissian A \& Dahl KD. Inhibin production by macaque granulosa cells from pre- and periovulatory follicles: regulation by gonadotropins and prostaglandin E2. Biology of Reproduction 199246 451-457.

9 Stouffer RL, Woodruff TK, Dahl KD, Hess DL, Mather JP \& Molskness TA. Human recombinant activin-A alters pituitary luteinizing hormone and follicle-stimulating hormone secretion, follicular development, and steroidogenesis, during the menstrual cycle in rhesus monkeys. Journal of Clinical Endocrinology and Metabolism $199377241-248$.

10 Fraser HM \& Tsonis CG. Manipulation of inhibin during the luteal-follicular phase transition of the primate menstrual cycle fails to affect FSH secretion. Journal of Endocrinology $1994 \mathbf{1 4 2}$ $181-186$ 
11 Molskness TA, Woodruff TK, Hess DL, Dahl KD \& Stouffer RL. Recombinant human inhibin-A administered early in the menstrual cycle alters concurrent pituitary and follicular, plus subsequent luteal, function in rhesus monkeys. Journal of Clinical Endocrinology and Metabolism $1996814002-4006$.

12 Groome NP, Illingworth PJ, O'Brien M, Cooke I, Ganesan TS, Baird DT \& McNeilly AS. Detection of dimeric inhibin throughout the human menstrual cycle by two-site enzyme immunoassay. Clinical Endocrinology $1994 \mathbf{4 0} 717-723$.

13 Sehested A, Juul AA, Andersson AM, Petersen JH, Jensen TK, Muller J \& Skakkebaek NE. Serum inhibin A and inhibin B in healthy prepubertal, pubertal, and adolescent girls and adult women: relation to age, stage of puberty, menstrual cycle, follicle-stimulating hormone, luteinizing hormone, and estradiol levels. Journal of Clinical Endocrinology and Metabolism $2000 \mathbf{8 5}$ 1634-1640.

14 Scheffer GJ, Broekmans FJ, Dorland M, Habbema JD, Looman CW \& te Velde ER. Antral follicle counts by transvaginal ultrasonography are related to age in women with proven natural fertility. Fertility and Sterility $1999 \mathbf{7 2} 845-851$.

15 Soules MR, Battaglia DE \& Klein NA. Inhibin and reproductive aging in women. Maturitas 199830 193-204.

16 Burger HG. Inhibin and reproductive aging. Experimental Gerontology 200035 33-39.

17 McLachlan RI, Robertson DM, Healy DL, de Kretser DM \& Burger HG. Plasma inhibin levels during gonadotropin-induced ovarian hyperstimulation for IVF: a new index of follicular function? Lancet $198611233-1234$.

18 Seifer DB, Lambert-Messerlian G, Hogan JW, Gardiner AC, Blazar AS \& Berk CA. Day 3 serum inhibin-B is predictive of assisted reproductive technologies outcome. Fertility and Sterility $199767110-114$.

19 Tinkanen H, Blauer M, Laippala P, Tuohimaa P \& Kujansuu E. Prognostic factors in controlled ovarian hyperstimulation. Fertility and Sterility $1999 \mathbf{7 2} 932-936$.

20 Creus M, Penarrubia J, Fabregues F, Vidal E, Carmona F, Casamitjana R, Vanrell JA \& Balasch J. Day 3 serum inhibin B and FSH and age as predictors of assisted reproduction treatment outcome. Human Reproduction 200015 2341-2346.

21 Dumesic DA, Damario MA, Session DR, Famuyide A, Lesnick TG, Thornhill AR \& McNeilly AS. Ovarian morphology and serum hormone markers as predictors of ovarian follicle recruitment by gonadotropins for in vitro fertilization. Journal of Clinical Endocrinology and Metabolism $2001862538-2543$.

22 Lockwood GM, Muttukrishna S, Groome NP, Knight PG \& Ledger WL. Circulating inhibins and activin A during GnRH-analogue down-regulation and ovarian hyperstimulation with recombinant FSH for in-vitro fertilization-embryo transfer. Clinical Endocrinology $199645741-748$.

23 Dzik A, Lambert-Messerlian G, Izzo VM, Soares JB, Pinotti JA \& Seifer DB. Inhibin B response to EFORT is associated with the outcome of oocyte retrieval in the subsequent in vitro fertilization cycle. Fertility and Sterility $2000 \mathbf{7 4} 1114-1117$.

24 Ravhon A, Lavery S, Michael S, Donaldson M, Margara R, Trew G \& Winston R. Dynamic assays of inhibin B and oestradiol following buserelin acetate administration as predictors of ovarian response in IVF. Human Reproduction $2000 \mathbf{1 5}$ 2297-2301.

25 Eldar-Geva T, Robertson DM, Cahir N, Groome N, Gabbe MP, Maclachlan V \& Healy DL. Relationship between serum inhibin $\mathrm{A}$ and $\mathrm{B}$ and ovarian follicle development after a daily fixed dose administration of recombinant follicle-stimulating hormone. Journal of Clinical Endocrinology and Metabolism $2000 \mathbf{8 5}$ 607-613.

26 Fawzy M, Lambert A, Harrison RF, Knight PG, Groome N, Hennelly B \& Robertson WR. Day 5 inhibin B levels in a treatment cycle are predictive of IVF outcome. Human Reproduction 200217 1535-1543.

27 Welt CK, Martin KA, Taylor AE, Lambert-Messerlian GM, Crowley WFJ, Smith JA, Schoenfeld DA \& Hall JE. Frequency modulation of follicle-stimulating hormone (FSH) during the luteal-follicular transition: evidence for FSH control of inhibin B in normal women. Journal of Clinical Endocrinology and Metabolism $1997822645-2652$.

28 Schipper I, Hop WC \& Fauser BC. The follicle-stimulating hormone (FSH) threshold/window concept examined by different interventions with exogenous FSH during the follicular phase of the normal menstrual cycle: duration, rather than magnitude, of FSH increase affects follicle development. Journal of Clinical Endocrinology and Metabolism 199883 1292-1298.

29 Hohmann FP, Laven JS, de Jong FH, Eijkemans MJ \& Fauser BC. Low-dose exogenous FSH initiated during the early, mid or late follicular phase can induce multiple dominant follicle development. Human Reproduction 200116 846-854.

30 van Santbrink EJ, Hop WC, van Dessel TJ, de Jong FH \& Fauser BC. Decremental follicle-stimulating hormone and dominant follicle development during the normal menstrual cycle. Fertility and Sterility $19956437-43$.

31 Fauser BC \& Van Heusden AM. Manipulation of human ovarian function: physiological concepts and clinical consequences. Endocrine Reviews $1997 \mathbf{1 8} 71-106$.

32 Pache TD, Wladimiroff JW, de Jong FH, Hop WC \& Fauser BC. Growth patterns of nondominant ovarian follicles during the normal menstrual cycle. Fertility and Sterility 1990 54 638-642.

33 Baird DT. A model for follicular selection and ovulation: lessons from superovulation. Journal of Steroid Biochemistry and Molecular Biology 198727 15-23.

34 Muttukrishna S, George L, Fowler PA, Groome NP \& Knight PG. Measurement of serum concentrations of inhibin-A (alpha-beta A dimer) during human pregnancy. Clinical Endocrinology 1995 42 391-397.

35 Burger HG, Groome NP \& Robertson DM. Both inhibin A and B respond to exogenous follicle-stimulating hormone in the follicular phase of the human menstrual cycle. Journal of Clinical Endocrinology and Metabolism $1998 \mathbf{8 3} 4167-4169$.

36 Bukman A \& Heineman MJ. Ovarian reserve testing and the use of prognostic models in patients with subfertility. Human Reproduction Update $20017581-590$.

37 Dickey RP, Taylor SN, Lu PY, Sartor BM, Rye PH \& Pyrzak R. Relationship of follicle numbers and estradiol levels to multiple implantation in 3608 intrauterine insemination cycles. Fertility and Sterility 200175 69-78.

38 Tur R, Barri PN, Coroleu B, Buxaderas R, Martinez F \& Balasch J. Risk factors for high-order multiple implantation after ovarian stimulation with gonadotrophins: evidence from a large series of 1878 consecutive pregnancies in a single centre. Human Reproduction $2001 \mathbf{1 6} 2124-2129$

39 Yong PY, Baird DT, Thong KJ, McNeilly AS \& Anderson RA. Prospective analysis of the relationships between the ovarian follicle cohort and basal FSH concentration, the inhibin response to exogenous FSH and ovarian follicle number at different stages of the normal menstrual cycle and after pituitary down-regulation. Human Reproduction 200318 35-44.

40 Hall JE, Welt CK \& Cramer DW. Inhibin A and inhibin B reflect ovarian function in assisted reproduction but are less useful at predicting outcome. Human Reproduction 199914 409-415.

Received 18 October 2004

Accepted 14 December 2004 